\title{
Should medical students volunteer to help during emergencies in public settings?
}

\author{
Cite as: CMAJ 2018 July 16;190:E866. doi: 10.1503/cmaj.109-5628
}

Posted on cmajnews.com on June 27, 2018.

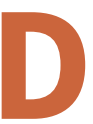
octors, nurses and other health professionals often volunteer to assist during medical emergencies on airplanes, at amateur sporting events, or in other public settings. But what about people training to work in health care? For medical students, comfort in these situations is often tied to how far along they are in their training.

In a recent blog entry, one medical student told the story of a peer volunteering to help during a medical emergency on an airplane. His friend was in the early years of his medical education and made it known that he could perform only basic tasks, such as taking vital signs. "What is your experience and level as a medical student?" wrote the blog author. "Are you just starting med school or are you in your last week? The abilities you have widely vary depending on where you are in your career."

Another medical student, in response to the blog post, recalled volunteering in a similar situation. This individual, however, was a fourth-year medical student. "I got up immediately because I didn't know what was wrong, how bad it was, or if anyone else on the plane would step up, plus I figured I should know something useful by this point," wrote the student. "Overall, I was infinitely more comfortable volunteering than I would have been as a preclinical student, but I was glad there were some experienced nurses there with me."

Health professionals appear to be more supportive of medical students helping in emergencies than the students themselves, according to a Medscape poll. Respondents to the poll included 459 medical students, 183 nurses, 872 physicians and 64 physician assistants. Only $23 \%$ of medical students said they should volunteer in emergencies regardless of year in school. But $40 \%$ of doctors said all medical students should offer help, as did $53 \%$ of nurses and $55 \%$ of physician assistants.

Medical students were more confident they could be helpful with more experience. A quarter of medical students said they would volunteer if in their third year of medical school. That increased to $32 \%$ for medical students in their fourth year. A small portion of medical students, $8 \%$, said they are not qualified to assist in

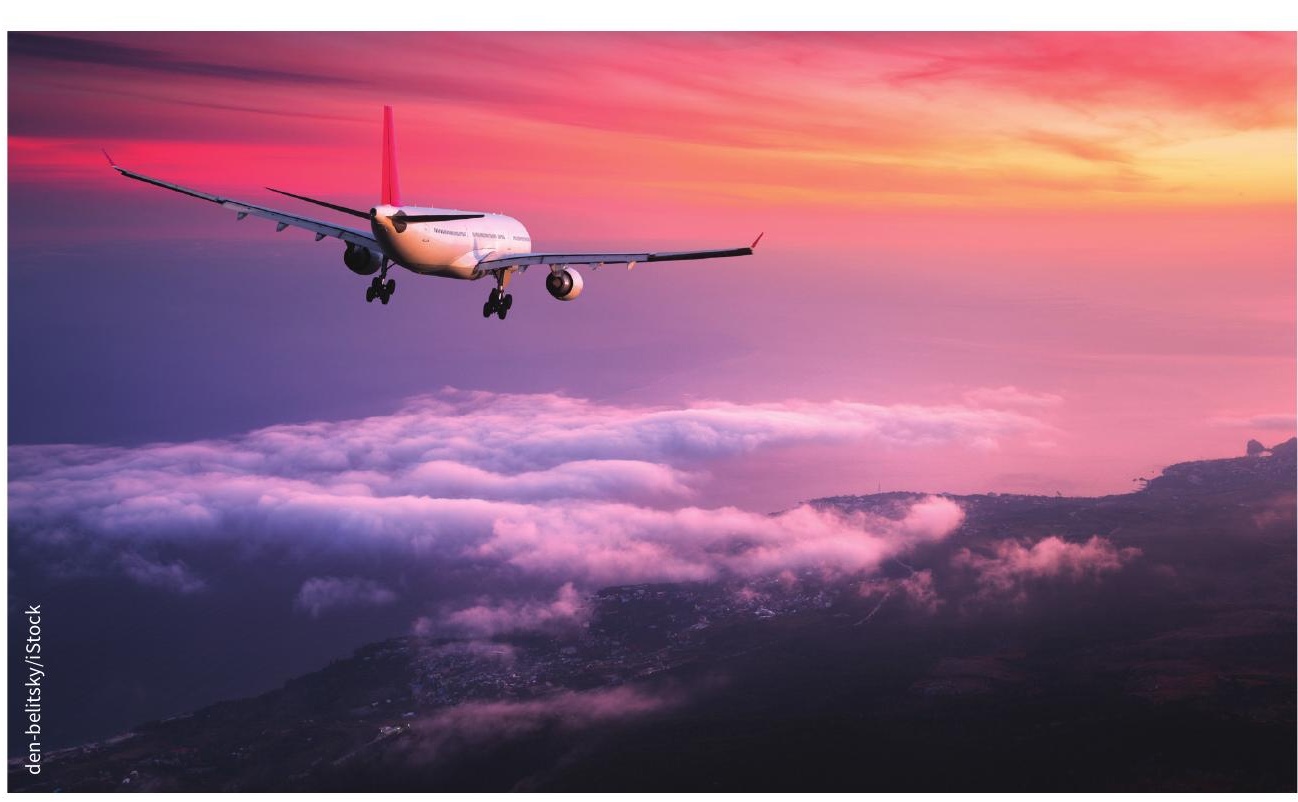

Medical students feel more comfortable responding to medical emergencies on airplanes or in other settings the further they are in their education.

medical emergencies, no matter how far into their medical education. This was also the opinion of $16 \%$ of nurses, $11 \%$ of physician assistants and $9 \%$ of physicians.

Though less comfortable in responding to medical emergencies in public settings, medical students expressed the strongest feelings of moral obligation to help (85\%), higher than doctors (83\%), physician assistants (78\%) and nurses (77\%).
Some medical students, like other health professionals, worry about the legal ramifications if outcomes aren't positive. Good Samaritan laws, however, protect all volunteers as long as they act in good faith and don't engage in gross negligence or misconduct. Still, some medical students wonder if the wide range of experience and skills among students makes the legal aspects more ambiguous.
"I feel, though, that the medicolegal aspect of this scenario is the more interesting and relevant issue," one medical students said in response to the blog post. "Whether you're in your first or final weeks of being a student, where are the boundaries of your involvement and decision-making?"

Roger Collier, CMAJ 